\title{
The Role of Attention Deficit-Hyperactivity Disorder in Disordered Eating Behaviors in Students of Sistan and Baluchestan University
}

\author{
Safoora Khoshdel Daryasari
}

MA in General Psychology, University of Sistan and Baluchestan, Zahedan, Iran

\begin{tabular}{ll} 
ARTICLE INFO & ABSTRACT \\
\cline { 2 - 2 } $\begin{array}{l}\text { Keywords: } \\
\text { Attention Deficit }\end{array} \begin{array}{l}\text { The purpose of this study was to investigate the role of attention } \\
\text { deficit hyperactivity disorder in disordered eating behaviors among } \\
\text { Behaviors } \\
\text { Students }\end{array}$ & $\begin{array}{l}\text { students of Sistan and Baluchestan University. This descriptive- } \\
\text { cross-sectional study was conducted on } 564 \text { students of Sistan and }\end{array}$ \\
Baluchestan University who were selected by non-random sampling \\
method. In total, 47 students with attention deficit-hyperactivity \\
disorder were diagnosed using diagnostic questionnaire of attention \\
deficit-hyperactivity disorder. Measurement tool was diagnostic \\
questionnaire of Connor's adult attention deficit-hyperactivity \\
disorder and Garner and Garfinkel's eating attitude test. Data were \\
analyzed by SPSS-23 using Pearson correlation and multiple \\
regressions. The results indicate the positive role of hyperactivity in \\
disordered eating attitudes and its relationship with bulimia nervosa \\
and behaviors related with oral control. Also, self-concept problems \\
in students with attention deficit-hyperactivity disorder had a \\
significant relationship with disordered food habits and predicted \\
disordered eating attitudes. According to the results, it seems that \\
students with attention deficit-hyperactivity disorder are exposed to \\
disordered eating behaviors, so further evaluations and studies and \\
appropriate therapies to prevent subsequent problems such as \\
educational problems and drug use and ... are recommended.
\end{tabular}

\section{Introduction}

Eating disorders are considered as behaviors that aim to achieve or maintain a slim form of the body (Tavolacci, 2015). According to the fifth edition of the Diagnostic and Statistical Manual of Mental Disorders (DSM-5), eating disorders in adulthood include anorexia nervosa, bulimia nervosa, binge-eating disorder and other eating disorders (Sadock et al., 2017; Vol. 2, p. 94). Anorexia nervosa with instability in eating behaviors, fear of weight gains and body dissatisfaction (Parker et al., 2016); bulimia nervosa is specified with periodic overeating and inappropriate compensatory behaviors (such as intentional vomiting) and undesired self-assessments about shape and weight (Trace et al, 2013). Binge eating disorder is also characterized by repeated eating behaviors, in which large amounts of food are consumed over a specific period of time. Other criteria include fast eating of food, lack of control over eating, eating until the satiety appears with discomfort, eating in loneliness, feeling hateful, shameful and guilty towards yourself and eating when the person is not hungry (Lewer et al, 2017). The lack of prognosis and lack of diagnostic criteria in the early stages of the disorder often leads to late detection. Eating disorders are common in young adults, such as university students, its outbreak is reported 8 to 17 percent in foreign

* Corresponding Author E-Mail Address: safoorakhoshde191@yahoo.com 
studies (Tavolacci, 2015). A research on female students of Shiraz University also showed that $0.7 \%$ of students had bulimia nervosa and $0.3 \%$ had binge eating disorders (Rezaei et al., 2015). One of the disorders associated with eating disorders is attention deficit hyperactivity disorder (Bleck et al., 2015; Kaisari et al, 2017). This disorder is one of the most common psychiatric disorders that begin early and, the most important symptoms include attention deficit, hyperactivity and impulsivity (Um et al, 2017). Definition of attention deficit -hyperactivity disorder in DSM-5 has also been updated in order to more accurately apply the experience of this disorder in adults. The minimum criteria for diagnosing ADHD in adults is five criteria, while for children and adolescents, the minimum number of criteria is six. Also, defects associated with attention deficit, hyperactivity and impulsivity should be present before the age of 12, and ADHD symptoms should not occur during the course of another psychological illness (American Psychiatric Association, 2013). Epidemiological studies indicate that there are attention deficithyperactivity symptoms in approximately $2.5 \%$ of adults (Sadock et al., 2017; Volume 3, p. 444). A lot of research has been carried out abroad in the study of the relationship of attention deficithyperactivity disorder with eating disorders. Researchers have found a positive relationship between ADHD symptoms and eating disorders, so that there was a positive and significant relationship between impulsivity symptoms and bulimia nervosa and binge-eating disorder. Also, hyperactivity has a positive role in avoiding eating behaviors (Kaisari et al, 2017). A research in a sample of adult patients confirmed the role of attention deficit-hyperactivity disorder in anorexia nervosa and bulimia nervosa (Sala et al., 2017). Also, the results of a study on 1165 Swedish adults showed that approximately one-third of ADHD patients had anorexia nervosa and bulimia nervosa and compensatory behaviors after eating (Svedlund et al., 2017). In another study, the positive relationship between attention deficit-hyperactivity disorder symptoms was confirmed by avoidance eating behaviors (Pennell et al, 2016). In investigating the relationship between ADHD symptoms and binge eating, the researchers confirmed the positive correlation between attention deficit and impulsivity in the binge-eating behaviors (Kaplan et al., 2016). In domestic studies, there is very limited attention to the relationship between ADHD and eating disorders, and more research has focused on the relationship between unhealthy diet and ADHD disorder. For example, the results of Azadbakht et al. (2012) showed that consuming sweet foods as well as fast foods significantly correlated with the incidence of ADHD in children and significantly increased the risk of attention deficit-hyperactivity disorder. Amani and Khajeh Mooghi (2005) also reported that children with ADHD, history of food allergies has been 2.5 times equal to other children. Increasing sugar intake was associated with an increase in the severity of ADHD in girls and drinking tea more than 3 cups per day with severity of disorder in boys. In general, considering that the wide range of ADHD symptoms from disturbance behaviors to emotional disorders can lead to psychological, educational and psychiatry consequences (Um et al, 2017), as well as the association of this disorder with eating disorders can cause more negative psychological, social and educational outcomes in students, and due to the lack of research on the relationship between these two disorders in the country, conducting this study to provide more accurate results are necessary. Therefore, the purpose of this study is to investigate the role of attention deficit hyperactivity disorder symptoms in disordered eating behaviors among students of Sistan and Baluchestan University. Given the topics discussed and the purpose of the research, the following question is asked:

- Can the symptoms of attention deficit hyperactivity disorder predict disordered eating behaviors in students? 


\section{Research Methodology}

This descriptive cross-sectional study was carried out on 613 students of dormitories affiliated to Sistan and Baluchestan University in the second semester 2017-2018 which were selected by nonrandom sampling method. In order to observe ethical considerations, the groups were assured for the confidentiality of their information. A total of 564 questionnaires were filled completely, which were analyzed. Two questionnaires were used in this study. Connor's adult attention deficithyperactivity disorder and Garner and Garfinkel's eating attitude test was used both of which were regulated as self-report and without name and surname. Then, the raw scores of each subscale in the diagnostic questionnaire of attention deficit-hyperactivity disorder was converted to standard $\mathrm{T}$ score, and scores higher than 60 were identified and selected as students with diagnostic questionnaire. In the final sample, 47 students ( 24 female students and 23 male students) had attention deficit-hyperactivity disorder.

The diagnostic questionnaire of Connor's adult attention deficit-hyperactivity disorder (1999) contains 26 items from zero to three points and four sub-scales and one general score; these are: attention deficit / memory problem (questions 3, 5, 17, 18, 21) hyperactivity, fidget (Questions 4, $6,10,11,23$ ), impulsivity (questions 1, 7, 8, 13, 20), problems related to self-concept (questions $9,15,16,25,26)$. The total score of all the questions is obtained. The highest score is 78 . The best cut-off point for diagnosis severe ADHD of adults, raw score equal to 50, equivalent to a T score equal to 60. So that the T scores between 60 and 70 higher than the average and higher than 70 are considered much higher than the average. Scores above 80 , in addition to show the severity of the problems, can also indicate the likelihood of exaggeration or blemish in symptoms (Conners et al, 2004). In a study on 424 adults, the reliability of this questionnaire was reported 0.75 (AmadorCampos et al, 2014). In the study of Arabgol and colleagues (2004), the reliability of this questionnaire was 0.81 by Cronbach's alpha. In the present study, Cronbach's alpha coefficient for internal consistency of the questionnaire questions was obtained for attention deficit 0.84; fidget 0.88 , and impulsivity 0.73 , and self-concept problems 0.86 . Another questionnaire used in this study was the eating attitude test, which was presented in 1989 by Garner and Garfinkel with 26 items. The questionnaire is the most commonly used standard tool for measuring the symptoms of nutritional disorders. Eating attitude test has three subscales of food habits (questions 1, 6, 7, 10, $11,12,14,16,17,22,23,24,26)$, tendency to eating (Questions 3, 4, 9, 18, 21, 25) and oral control (questions 2, 5, 8, 13, 15, 19, 20). The questionnaire scoring in questions 1 to 25 is scored as always $=3$, mostly $=2$, often $=1$, sometimes $=0$, rarely $=0$, never $=0$, and the phrase 26 is scored in reverse. The lowest score assigned to the person is zero and the highest score is 78. Scores 0 to 20 indicate lack of problem, 20 to 36 need to be reviewed and treatment, and 36 to 78 indicate severe disorder in body and weight. Garner et al. have reported the reliability coefficient of the questionnaire by an internal consistency 0.94 and a test-retest method 0.84 . In another study, the coefficient of validity of this questionnaire was calculated with a diagnostic sensitivity of 0.40 and a coefficient of 0.84 . Also, the Cronbach's alpha coefficient for each subscale was reported 0.75 (Nunes, 2004; citing from Agha Gadi and Etemadi, 2014). Pourghasem Gargari and colleagues (2010) reported the validity of this questionnaire with Cronbach's alpha 76\% and its reliability with a correlation test 0.80 . In the present study, Cronbach's alpha was used to examine the internal consistency of the questions. For the total score of eating attitude questionnaire, the coefficient of 0.73 was reported.

Data were analyzed using SPSS-23 software using Pearson correlation test and multivariate regression. 


\section{Finding}

In this study, 564 students were studied in order to determine the relationship between attention deficit hyperactivity disorders and disordered eating behaviors among students of Sistan and Baluchestan University in 2018. Students were screened using Conner's adult test for the presence and absence of attention deficit and hyperactivity disorder symptoms. Finally, 47 (8.3\%) students were diagnosed with attention deficit hyperactivity disorder. Of these, 24 were female $(51.1 \%)$ and 23 were male $(48.9 \%)$. In the index of attention deficit and hyperactivity disorder, 18 female students $(75 \%)$ and 3 male students (13\%) reported symptoms above the mean, and 6 female students $(25 \%)$ and 20 male students $(87 \%)$ reported much above average. Also, in the eating attitude index, 13 female students $(54.2 \%)$ and 13 male students (56.5\%) had no nutritional problems and 11 female students (45.8\%) and 10 male students $(43.5 \%)$ showed moderate nutrition problems.

Correlation between the different dimensions of attention deficit hyperactivity disorder and eating attitude are shown in Table 1. The results show that the overall score of attention deficit hyperactivity disorder has a direct and significant relationship with total score of eating attitude ( $\mathrm{r}$ $=0 / 29, p=0 / 05)$, and sub-scales of oral control $(\mathrm{r}=0 / 29, \mathrm{P}<0.05)$. Also, among the dimensions of the attention deficit-hyperactivity disorder, the problems related to self-concept with dietary habits ( $\mathrm{p}<0.01, \mathrm{r}=0.39$ ) fidget / hyperactivity has a positive and significant relationship with total score of eating attitude $(\mathrm{r}=0.32, \mathrm{p}<0.05)$, and the components of tendency to eating $(\mathrm{p}<0.05, \mathrm{r}=$ $0.32)$ and oral control $(\mathrm{r}=0.33, \mathrm{p}<0.01)$.

Table 1: Correlation coefficient between different dimensions of attention deficit hyperactivity disorder and eating attitude

\begin{tabular}{|c|c|c|c|c|}
\hline $\begin{array}{l}\text { Total } \\
\text { score }\end{array}$ & $\begin{array}{c}\text { Oral } \\
\text { control }\end{array}$ & $\begin{array}{l}\text { Tendency } \\
\text { to eating }\end{array}$ & $\begin{array}{l}\text { Food } \\
\text { Habits }\end{array}$ & $\begin{array}{l}\text { Eating Attitude } \\
\text { Attention deficit hyperactivity disorder }\end{array}$ \\
\hline-0.12 & -0.07 & -0.11 & -0.08 & Attention deficit / Memory Problem \\
\hline $0.32 *$ & $0.33 *$ & $0.32 *$ & 0.06 & Fidget-hyperactivity \\
\hline-0.01 & 0.10 & 0.06 & -0.18 & Impulsivity \\
\hline 0.27 & 0.10 & 0.10 & $0.39 * *$ & Problems related to self-concept \\
\hline $0.29 *$ & $0.29 *$ & 0.23 & 0.11 & Total score \\
\hline
\end{tabular}

According to Table 2, stepwise regression was used to predict the general score of eating attitude from attention deficit-hyperactivity disorder (ADHD) components and the results showed that fidget / hyperactivity components and problems related to self-concept entered the equation. Considering the amount of determination coefficient equal to 0.20 and the adjusted coefficient of determination equal to 0.17 , it can be concluded that about $3 \%$ of the variance of the total score of eating attitude is explained by the components of fidget / hyperactivity and problems related to self-concept. In general, fidget/ hyperactive $(\mathrm{p}=0.01$ and Beta $=0.361)$ and self-concept problems $(\mathrm{p}=0.02$ and Beta $=0.319)$ were reported positive prediction of eating attitude. 
Table 2: The results of stepwise regression of the overall score of eating attitude from the components of the attention deficit-hyperactivity disorder

\begin{tabular}{|l|c|c|c|c|c|c|c|c|}
\hline Variable & $\mathrm{R}$ & $R^{2}$ & $\begin{array}{c}\text { Adjust R } \\
\text { Square }\end{array}$ & $\mathrm{B}$ & $\begin{array}{c}\text { S.D. } \\
\text { Error }\end{array}$ & Beta & $\mathrm{t}$ & Sig \\
\hline Fidget/hyperactivity & 0.32 & 0.10 & 0.08 & 0.689 & 0.258 & 0.361 & 2.670 & 0.01 \\
\hline $\begin{array}{l}\text { Problems related to } \\
\text { self-concept }\end{array}$ & 0.45 & 0.20 & 0.17 & 0.624 & 0.265 & 0.319 & 2.359 & 0.02 \\
\hline
\end{tabular}

\section{Discussion and conclusion}

The results of this study indicated that the prevalence of attention deficit-hyperactivity disorder among the students of Sistan and Baluchestan University is $8.3 \%$. The present study showed a relatively high prevalence of attention deficit-hyperactivity disorder in the studied population, which is a confirmation of previous studies. So, the results of the study by Bakhshani et al. (2011) in the study of the prevalence of this disorder in 450 students of Sistan and Baluchestan University showed that $9.7 \%$ in the attention deficit index, $7.9 \%$ in the impulsivity index, $9.4 \%$ in the selfconcept problem index showed symptoms above average and much higher than the average. The prevalence of this disorder in the study of Sadeghi Movahed and colleagues (2012) was reported 8.6\% in 582 students of Ardabil University of Medical Sciences. Also, in the present study, the prevalence of nutritional problems in patients with attention deficit-hyperactivity disorder was moderately downward, so that $(55.3 \%)$ of the students were without nutritional problems and $(44.7 \%)$ showed problems in eating and nutrition.

The results of this study in investigating the role of attention deficit-hyperactivity disorder in disordered eating behaviors showed that there is a significant relationship between attention deficit-hyperactivity disorder and disordered eating behaviors. There was also a direct and significant relationship between sub-scale of fidget/ hyperactivity and bulimia nervosa. Hyperactivity was reported predicting disordered eating behaviors. This finding is consistent with the results of Sala et al. (2017) and Svedlund et al. (2017). For example, the results of Sala et al. (2017) confirmed the role of hyperactivity in bulimia nervosa.

In explaining this finding that there is a significant relationship between hyperactivity and fidget with bulimia nervosa, it can be pointed out the problems of people with attention deficithyperactivity disorder in executive function. As it is clear, people suffering from this disorder have the defect of impulse control, which faces executive function of these individuals with problem. Studies have confirmed that disorder in preconfrontal cortex, which is responsible for controlling environmental stimuli, and the underacting forebrain, can create problems of bulimia nervosa in attention deficit-hyperactivity disorder (Zwaan et al., 2011; Reinblatt, 2015). Also, the relationship between hyperactivity and non-inhibition in ADHD patients with bulimia nervosa can be explained by some genetic traits. It has been suggested that dopaminergic genes, especially dopamine receptors D4, are independently associated with attention deficit- hyperactivity disorder symptoms and eating disorders. In fact, studies by examining the dopamine reward pathways in people with ADHD have concluded that people with ADHD have fewer D4 receptors in their reward circuits, and defect in dopaminergic receptors can help to bulimia nervosa and eating disorders in the affected population (Tong et al, 2017).

The results of the present study also showed that fidget / hyperactivity is associated with oral control and avoidance behaviors in eating. These results are in line with Kaisari et al. (2017) and Pennell et al. (2016). For example, Pennell et al (2016) confirmed the positive role of attention 
deficit- hyperactivity disorder symptoms in the prevention of eating avoidance behaviors. In explaining the relationship of fidget / hyperactivity and oral control (such as avoiding food in hunger, prolonging eating and controlling food intake, etc.), many researches have considered drug treatment of attention deficit- hyperactivity disorder. These studies have shown that methylphenidate (or ritalin), which is highly effective in the treatment of ADHD, can have significant effects on appetite and cause lack of feeling hunger (Kaisari et al, 2017). For example, a study by Levy et al. (2009) found that treatment with methylphenidate in overweight people with ADHD can lead to lack of feeling hunger, avoidance of food and a significant reduction in overweight patients (Ptacek et al, 2016).

The results also showed that there is a positive and significant relationship between self-concept problems in ADHD patients with undesired food habits and the problem in self-concept has a positive role in explaining disordered eating behaviors. This finding suggests that low self-esteem and low self-confidence in people with ADHD can increase disordered eating behaviors such as panic and anxiety about overweight, guilty feeling arising from eating, excessive exercise for calories consumed, severe diets and more. Few studies have investigated this relationship in people with ADHD. For example, the results of the study showed that people with ADHD often have low social cognition and a wide range of emotional problems, such as low self-esteem, social anxiety, and incompetence feelings that all these negative emotions can increase the risk of disordered eating behaviors and avoidance eating behaviors (Råstam et al., 2013; Gau, 2010; citing from Tong et al, 2017). In general, research has shown that nutritional problems such as food constraints, problems related to bulimia nervosa and severe diets are directly related to low self-esteem and unstable self-concept (Kansi et al, 2003), and low self-esteem increases the likelihood of eating disorders significantly (Mora et al., 2017).

From the results obtained in this study, it can be concluded that attention deficit-hyperactivity disorder symptoms can play an important role in the occurrence of disordered eating behaviors. Given the fact that this study in the country is the first study that explicitly investigates the role of attention deficit-hyperactivity disorder in the nutritional disorders, investigating this issue can be considered as one of the points in this study. However, the present study was confronted with limitations, such as sampling limited to the students of Sistan and Baluchestan University in the academic year of 2017-2018. Therefore, it is suggested that future studies to be targeted other educational levels, different ages and other cities of the country. Also, the lack of studies conducted in this study faced the research findings with limitations, which suggests that more extensive studies are needed to better generalize the results. Among other limitations of this study, the lack of attention to the history of using psychiatric drugs in the study group can be referred, which is used in the treatment of attention deficit-hyperactivity disorder symptoms, therefore, in order to provide more accurate results on the effect of these drugs on unhealthy eating, future studies should consider the use of drug, type of drug, amount of drug and duration of treatment in affected patients. Also, due to the relatively high prevalence of ADHD in this study, it is recommended to prioritize counseling centers of universities, identify people with ADHD and provide appropriate educational and therapeutic strategies to reduce the adverse effects of this disorder.

\section{References}

Aghagedi, P. \& Etemadi, A. (2014). The Effectiveness of Cognitive-Behavioral Stress Management Training on Changing the Attitude of Sub-scales of Eating Disorders in Female Students. Journal of Social Cognition, 3, (Special Issue), 58-44. 
Amador-Campos, J., Gómez-Benito, J., \& Ramos-Quiroga, J. (2014). The conners' adult ADHD rating scales--short self-report and observer forms: psychometric properties of the Catalan version. Journal of Attention Disorders, 18 (8), 671-9.

Amani, R. \& Khajeh Mooghi, N. (2005). Comparison of nutritional pattern of primary school children with attention deficit hyperactivity disorder with healthy children. Journal of Iran University of Medical Sciences, 12 (45), 42-37.

American Psychiatric Association. (2013). Attention Deficit/ Hyperactivity Disorder. American psychiatric publishing, http://www.adhd-liitto.fi/sites/default/files/adhd_fact_sheet.pdf

Arab, F., Hayati, M., \& Hadid, M. (2004). Prevalence of attention-deficit hyperactivity disorder in a group of students. Journal of Cognitive Science, 6 (1), 78-73.

Azadbakht, L., Rohani, S. M. H., Esmaeilzadeh, A. (2010). Food consumption pattern and its relation to hyperactivity disorder and lack of attention and concentration among Iranian children. Zahedan Journal of Research in Medical Sciences, 14 (2), 30-21.

Bakhshani, N., Raghibi, M., \& Babaei, S. (2011). Frequency of attention deficit-hyperactivity in adult students in Sistan and Baluchestan University. Zahedan Journal of Research in Medical Sciences, 13 (7), 22-18.

Bleck, JR., DeBate, RD., \& Olivardia, R. (2015). The Comorbidity of ADHD and Eating Disorders in a Nationally Representative Sample. The Journal of Behavioral Health Services \& Research, $42(4), 437-51$.

Conners, K., Erhardt, D. \& Sparrow, E. (2004). Conner's Adult ADHD Rating Scales-Self-Report: Short Version (CAARS-S: S). North Tonawanda, New York: Multi-Health systems.

Kaisari, P., Dourish, C., \& Higgs, S. (2017). Attention Deficit Hyperactivity Disorder (ADHD) and disordered eating behaviour: A systematic review and a framework for future research. Clinical Psychology Review, 53., 109-121.

Kansi, J., Wichstrøm, L., \& Bergman, L. (2003). Eating Problems and the Self-Concept: Results Based on a Representative Sample of Norwegian Adolescent Girls. Journal of Youth and Adolescence, 32 (5), 325-335.

Kaplan, A., Howlett, A., Yilmaz, Z., \& Levitan, R. (2016) The Relationship between Binge Eating and Attention Deficit Hyperactivity Disorder. Bio-Psycho-Social Contributions to Understanding Eating Disorders, 3-15. https://doi.org/10.1007

Lewer, M., Bauer, A., Hartmann, A. S., \& Vocks, S. (2017). Different Facets of Body Image Disturbance in Binge Eating Disorder: A Review. Nutrients, 9 (12), 1294. http://doi.org/10.3390/nu9121294

Mora, F., Fernandez Rojo, S., Banzo, C., \& Quintero, J. (2017). The impact of self-esteem on eating disorders. European Psychiatry, 41, Page S558.

Parker, E. k., Faruquie, S., Anderson, G., Gomes, L. \& Kennedy, A., Wearne, C., ... Clarke, S. D. (2016). Higher Caloric Refeeding Is Safe in Hospitalised Adolescent Patients with Restrictive Eating Disorders. Journal of Nutrition and Metabolism, 2016, 5168978. 9 pages. http://dx.doi.org/10.1155/2016/5168978 
Pennell, A., Couturier, J., Grant, C., \& Johnson, N. (2016). Severe avoidant/restrictive food intake disorder and coexisting stimulant treated attention deficit hyperactivity disorder. International Journal of Eating Disorders, 49 (4), 1036-1039.

Pourghasem Gargari, B., Hamed Behzad, M., Seyed Sajjadi, N., Koushavar, D., \& Karami, S. (2010). Association of Body Mass Index with Nutritional Attitudes in High School Students of Tabriz Girl's high school. Medical Journal of Tabriz University of Medical Sciences, 32 (3), 29-24.

Ptacek, R., Stefano, G. B., Weissenberger, S., Akotia, D., Raboch, J., Papezova, H., ... Goetz, M. (2016). Attention deficit hyperactivity disorder and disordered eating behaviors: links, risks, and challenges faced. Neuropsychiatric Disease and Treatment, 12, 571-579. http://doi.org/10.2147/NDT.S68763

Reinblatt, S. (2015). Are Eating Disorders Related to Attention Deficit/Hyperactivity Disorder? Current treatment options in psychiatry, 2 (4), 402-412.

Rezaei, M., Aflak Seir, A., \& Ghayour, M. (2015). Prevalence of Eating Disorder and Obesity among Female Students of Shiraz University. Journal of Nursing Research, 10 (3), 42-36.

Sadeghi Movahed, F., Movlavi, P., Samadzadeh, M., Shahbazzadegan, B. \& Asgari Moqadam, R. (2012). Prevalence of attention deficit- hyperactivity disorder in dormitory students of Ardabil University of Medical Sciences. Ardabil University of Medical Sciences Journal, 12 (5), 94-87.

Sadock, B. J., Sadock; V. A., Roeis P. (2017). Summary of Psychiatry: Behavioral Sciences / Clinical Psychiatry, Farzin Rezaie Translation, Tehran, Arjmand Publication.

Sala, L., Martinotti, G., Carenti, M. L., Romo, L., Oumaya, M., Pham-Scottez, A., ... Janiri, L. (2017). Attention-deficit/hyperactivity disorder symptoms and psychological comorbidity in eating disorder patients. Eating and Weight Disorders. doi: 10.1007/s40519-017-0395-8.

Svedlund, N., Norring, C., Ginsberg, Y., \& Hausswolff-Juhlin, Y. (2017). Symptoms of Attention Deficit Hyperactivity Disorder (ADHD) among adult eating disorder patients. BMC Psychiatry, 17, Page 19.

Tavolacci, M., Grigioni, S., Richard, L., Meyrignac, G., Déchelotte, P., \& Ladner, J. (2015). Eating Disorders and Associated Health Risks among University Students. Journal of Nutrition Education and Behavior, 47 (5), 412-20.

Tong, L., Shi, H., \& Li, X. (2017). Associations among ADHD, Abnormal Eating and Overweight in a non-clinical sample of Asian children. Scientific Reports, 7 (1), 2844.

Trace, S., Baker, J., Peñas-Lledó, E., \& Bulik, C. (2013). The genetics of eating disorders. Annual Review of Clinical Psychology, 9, 589-620.

Um, Y., Hong, S., Jeong, J. (2017). Sleep Problems as Predictors in Attention-Deficit Hyperactivity Disorder: Causal Mechanisms, Consequences and Treatment. Clinical Psychopharmacology and Neuroscience, 15, (1), 9-18.

de Zwaan M., Gruß B., Müller A., Philipsen A., Graap H., Martin A., Glaesmer H., Hilbert A. (2011). Association between Obesity and Adult Attention-Deficit/Hyperactivity Disorder in a German Community-Based Sample. Obes Facts, 4:204-211 